\title{
Long-term Outcomes of Tension-free Vaginal Tape Procedure for Treatment of Female Stress Urinary Incontinence with Intrinsic Sphincter Deficiency
}

\author{
Gwoan-Youb Choo, Dae Hyun Kim, Hyoung Keun Park, Sung-Hyun Paick, Yong-Soo Lho, Hyeong-Gon Kim \\ Department of Urology, Konkuk University School of Medicine, Seoul, Korea
}

\begin{abstract}
Purpose: To assess the long-term outcomes of tension-free vaginal tape (TVT) for stress urinary incontinence (SUI) with intrinsic sphincter deficiency (ISD) and to identify influencing factors for failure in these cases.

Methods: A total of 136 women who underwent TVT procedures with minimum follow-up duration of 3 years were included in the study. Patients were divided into two groups (non-ISD and ISD groups) based on preoperative urodynamic studies. Patient outcomes were assessed from retrospective chart review and telephone research. Cure was defined as the subjective resolution of SUI in any circumstances. Improvement was defined as the subjective improvement of SUI without complete resolution. Failure was defined as the subjective lack of improvement of SUI. Patients in ISD group were subdivided into two subgroups (cure and non-cure groups) and were compared to identify influencing factors for TVT procedure failure.

Results: Eighty-nine patients were in non-ISD group, and 47 in ISD group. The mean follow-up durations were $50.3 \pm 9.2$ and $49.7 \pm 9.7$ months, respectively. Subjective cure rate was $75.3 \%$ for non-ISD group, and $76.7 \%$ for ISD group $(\mathrm{P}>0.05)$. Improvement rate was $6.7 \%$ for non-ISD group, and $2.1 \%$ for ISD group $(\mathrm{P}>0.05)$. Satisfaction scores was $3.8 \pm 1.2$ points in the non-ISD group, and $3.5 \pm 1.2$ points in ISD group $(\mathrm{P}>0.05)$. In ISD subgroups, VLPP was $41.9 \pm 12.0 \mathrm{cmH}_{2} \mathrm{O}$ for non-cure group, and $50.5 \pm 8.6 \mathrm{cmH}_{2} \mathrm{O}$ for cure group, and was the only factor that showed significant statistical difference between the two subgroups $(\mathrm{P}=0.011)$.

Conclusions: With our long-term results, TVT is an effective treatment even in women with ISD. However, ISD patients with low VLPP should be counseled carefully about TVT outcome.
\end{abstract}

Keywords: Stress urinary incontinence; Suburethral slings; Urodynamics

\section{INTRODUCTION}

Stress urinary incontinence (SUI) is a highly prevalent condition that has a significant impact on health related quality of life. Although multiple behavioral and operative treatments exist, midurethral slings are becoming the gold standard for correction of SUI in women.

SUI due to intrinsic sphincter deficiency (ISD) is the most clinical challenges in anti-incontinence operation. In ISD, the urethral closure mechanism is considered to function poorly and historically, pubovaginal slings have been the procedure of choice.

Tension-free vaginal tape (TVT) procedure has been shown to be a safe and effective treatment for stress urinary incontinence with high success rate and this procedure had been employed in patients with ISD. The success rates of TVT procedure in these patients were acceptable with success rate of 73 to $82 \%$ [1-3]. However, most reports were short term follow-up studies and there is only one simple long-term observation study.

The aim of our study was to compare the long-term clinical outcomes of the TVT procedure in ISD and non-ISD patients and identify the influencing factors for TVT procedure failure
Corresponding author: Hyeong Gon Kim

Department of Urology, Konkuk University Medical Center, Konkuk University School of Medicine, 120 Neungdong-ro, Gwangjin-gu, Seoul 143-729, Korea Tel: +82-2-2030-7672 / Fax: +82-2-2030-5319 / E-mail: 20040097@kuh.ac.kr Submitted: November 21, 2011 / Accepted after revision: December 22, 2011
This is an Open Access article distributed under the terms of the Creative Commons Attribution Non-Commercial License (http://creativecommons.org/licenses/by-nc/3.0/) which permits unrestricted non-commercial use, distribution, and reproduction in any medium, provided the original work is properly cited. 
in patients with ISD.

\section{MATERIALS AND METHODS}

We retrospectively assessed patients who were urodynamically diagnosed as stress urinary incontinence and those who underwent TVT procedure between 2005 and July 2008. A total of 136 patients with minimum follow-up duration of 3 years were included in the study. All the TVT procedures were performed by one experienced surgeon.

ISD was defined by a maximum urethral closure pressure (MUCP) less than $20 \mathrm{cmH}_{2} \mathrm{O}$ or a Valsalva leak point pressure (VLPP) less than $60 \mathrm{cmH}_{2} \mathrm{O}$ [4]. Patients were divided into two groups, the non-ISD group and the ISD group. Demographics, urodynamic study, urethral hypermobility, and surgical variables were compared between the two groups. Urethral hypermobility was defined by a straining Q-tip angle greater than 30 degrees from the horizontal [5].

Patient outcomes were assessed from the questionnaires by the retrospective chart review or/and telephone research. Satisfaction scores were assessed by a 5-point Likert-type scale as 1 (completely dissatisfied), 2 (mostly dissatisfied), 3 (neutral), 4 (mostly satisfied), or 5 (completely satisfied). Cure was defined as no urine leakage at all in any circumstances, and improvement was defined as having some urine leakage but over 4 points out of 5 in the satisfaction inquiry. Failure was defined as having some urine leakage and at most 3 points or less out of 5 in the satisfaction inquiry.

Cure rate, improvement rate, failure rate, and satisfaction score after TVT failure were compared between the two groups.

Patients in ISD group were subdivided again into two subgroups, the cure group and non-cure group. Demographics, urodynamic studies, and surgical variables were compared between the two subgroups to identify prognostic factors for TVT failure.

Student's t-test and chi-square test were applied. Reported Pvalues were 2 -sided and a P-value of less than 0.05 was considered statistically significant for all comparisons. Statistical analysis was performed with commercial statistical software SPSS ver. 17.0 (SPSS Inc., Chicago, IL, USA).

\section{RESULTS}

Demographic variables were comparable between the non-ISD group $(n=89)$ and the ISD group $(n=47)$ (Table 1). Mean age,
Table 1. Baseline characteristics of non-ISD and ISD groups

\begin{tabular}{lccc}
\hline Variable & Non-ISD & ISD & P-value \\
\hline No. of patients & \multicolumn{1}{c}{89} & 47 & \\
Age $(\mathrm{yr})$ & $57.0 \pm 8.2$ & $58.7 \pm 11.9$ & 0.377 \\
Body mass index $\left(\mathrm{kg} / \mathrm{m}^{2}\right)$ & $24.6 \pm 3.2$ & $25.0 \pm 3.1$ & 0.496 \\
Follow-up duration $(\mathrm{mo})$ & $50.3 \pm 9.2$ & $49.7 \pm 9.7$ & 0.713 \\
Previous anti-incontinence & $2(2.2)$ & $2(4.3)$ & 0.513 \\
$\quad$ surgery & & & \\
Previous pelvic surgery & $6(6.7)$ & $4(8.5)$ & 0.710 \\
Concomitant medical disease & $26(29.2)$ & $22(46.8)$ & 0.041 \\
Concomitant cystocele repair & $8(9.0)$ & $2(4.3)$ & 0.123 \\
Urgency & $42(47.2)$ & $27(57.4)$ & 0.259 \\
Urge incontinence & $30(33.7)$ & $20(42.6)$ & 0.313 \\
Preoperative urodynamic parameters & & \\
Uninhibited contraction & $2(2.2)$ & $4(8.5)$ & 0.160 \\
Qmax (mL/sec) & $21.1 \pm 7.9$ & $22.4 \pm 9.1$ & 0.410 \\
PVR (mL) & $22.7 \pm 26.8$ & $21.4 \pm 29.6$ & 0.819 \\
MUCP $\left(\mathrm{cmH} \mathrm{H}_{2} \mathrm{O}\right)$ & $79.5 \pm 46.9$ & $57.3 \pm 28.3$ & 0.004 \\
VLPP $\left(\mathrm{cmH}{ }_{2} \mathrm{O}\right)$ & $78.7 \pm 14.5$ & $48.4 \pm 10.0$ & 0.000 \\
Urethral hypermobility & $57(64.0)$ & $25(53.2)$ & 0.222 \\
\hline
\end{tabular}

Values are presented as mean \pm SD or number (\%).

ISD, intrinsic sphincter deficiency; Qmax, maximum urinary flow rate; PVR, post voided residual urine; MUCP, maximum urethral closure pressure; VLPP, Valsalva leak point pressure.

follow-up duration, body mass index, concomitant cystocele repair and previous operation history also showed no significant differences between the two groups. However, the prevalence of concomitant medical diseases, such as diabetes, hypertension, and cerebrovascular disease was higher in the ISD group.

MUCP and VLPP in the non-ISD group were $79.5 \pm 46.9$ and $78.7 \pm 14.5 \mathrm{cmH}_{2} \mathrm{O}$, and in the ISD group, they were $57.3 \pm 28.3$ and $48.4 \pm 10.0 \mathrm{cmH}_{2} \mathrm{O}(\mathrm{P}<0.05)$. Maximum urinary flow rate (Qmax), post voided residual urine (PVR), and urethral hypermobility rate were not significantly different between the two groups (Table 1).

The cure rate of TVT showed no difference between the two groups. Sixty-seven (75.3\%) of 89 patients were cured in nonISD group and 36 of 47 patients (76.6\%) were cured in ISD group. Satisfaction scores in the non-ISD and ISD groups were $3.8 \pm 1.2$ points and $3.5 \pm 1.2$ points, respectively and were not different between the two groups (Table 2).

In non-ISD group, 2 patients had vaginal erosion and 1 patient had urinary tract infection during follow-up duration. In ISD group, no patient had any kind of erosion and 1 patient had 
Table 2. Long-term clinical outcomes of non-ISD and ISD group

\begin{tabular}{lccc}
\hline & Non-ISD & ISD & P-value \\
\hline Subjective outcome & & & \\
Cure & $67(75.3)$ & $36(76.6)$ & 0.866 \\
Improvement & $6(6.7)$ & $1(2.1)$ & 0.179 \\
Failure & $16(18.0)$ & $10(21.3)$ & 0.886 \\
Satisfaction (points) & $3.8 \pm 1.2$ & $3.5 \pm 1.2$ & 0.433 \\
Very satisfied & $27(30.3)$ & $12(25.5)$ & \\
Satisfied & $34(38.2)$ & $16(34.0)$ & \\
No change & $13(14.6)$ & $11(23.4)$ & \\
Dissatisfied & $7(7.9)$ & $2(4.3)$ & \\
Very dissatisfied & $8(9.0)$ & $6(12.8)$ & \\
\hline
\end{tabular}

Values are presented as number (\%) or mean \pm SD.

ISD, intrinsic sphincter deficiency.

urinary retention.

ISD group was subdivided into cure group $(\mathrm{n}=36)$ and noncure group $(\mathrm{n}=11)$. Age, concomitant medical disease, concomitant overactive bladder symptoms, MUCP and urethral hypermobility were not statistically different between the two subgroups. The only significant parameter was the VLPP. VLPP of the cure and non-cure subgroups were $41.9 \pm 12.0 \mathrm{cmH}_{2} \mathrm{O}$ and $50.5 \pm 8.6 \mathrm{cmH}_{2} \mathrm{O}$, which was statistically significant $(\mathrm{P}=0.011)$ (Table 3$)$.

\section{DISCUSSION}

The TVT procedure has become one of the most popular techniques for treating SUI because of its ease and effectiveness. A published series [6,7] with a long follow-up duration showed good continence rates after the TVT procedure.

However, there is a controversy about the long term efficacy of the TVT procedure in women with ISD. Doo et al. [8] reported five year follow-up results 31 patients with VLPP below 60 $\mathrm{cmH}_{2} \mathrm{O}$ and 64 with VLPP above $60 \mathrm{cmH}_{2} \mathrm{O}$. Cure rates were $51.6 \%$ and $82.8 \%$, respectively and the success rate of the ISD group was significantly lower. Paick et al. [2] also reported significantly low success rate in the group below $60 \mathrm{cmH}_{2} \mathrm{O}$ compared the group above $60 \mathrm{cmH}_{2} \mathrm{O}$.

On the contrary, one study reported that the similar success rates between patients with VLPP below $60 \mathrm{cmH}_{2} \mathrm{O}$ and with VLPP above $60 \mathrm{cmH}_{2} \mathrm{O}$; success rates were $74.2 \%$ and $67.2 \%$, respectively [9]. Another study compared 61 women with MUCP less than $20 \mathrm{cmH}_{2} \mathrm{O}$ and 204 women with MUCP above
Table 3. Multivariate analysis of variables as determinants for TVT failure in ISD women

\begin{tabular}{lccc}
\hline Variable & Cure & Non-cure & P-value \\
\hline No. of patients & 36 & 11 & \\
Age $(\mathrm{yr})$ & $57.9 \pm 11.8$ & $61.3 \pm 12.5$ & 0.419 \\
BMI $\left(\mathrm{kg} / \mathrm{m}^{2}\right)$ & $25.1 \pm 3.3$ & $24.6 \pm 2.2$ & 0.693 \\
Concomitant medical disease & $15(41.6)$ & $6(54.5)$ & 0.463 \\
Urgency & $19(52.8)$ & $8(72.7)$ & 0.278 \\
Urge incontinence & $13(36.1)$ & $7(63.6)$ & 0.068 \\
Preoperative urodynamic parameters & & \\
Qmax (mL/sec) & $23.3 \pm 9.6$ & $19.3 \pm 6.7$ & 0.225 \\
PVR $(\mathrm{mL})$ & $15.8 \pm 21.7$ & $43.3 \pm 45.3$ & 0.135 \\
MUCP $\left(\mathrm{cmH} \mathrm{H}_{2} \mathrm{O}\right)$ & $55.7 \pm 29.1$ & $62.6 \pm 26.2$ & 0.506 \\
VLPP $\left(\mathrm{cm} \mathrm{H}_{2} \mathrm{O}\right)$ & $50.5 \pm 8.6$ & $41.9 \pm 12.0$ & 0.011 \\
Urethral hypermobility & $15(41.6)$ & $5(45.5)$ & 0.829 \\
Postoperative Hb change & $1.7 \pm 1.6$ & $1.1 \pm 0.4$ & 0.198 \\
$\quad$ (g/dL) & & & \\
\hline
\end{tabular}

Values are presented as mean \pm SD or number (\%).

TVT, tension-free vaginal tape; ISD, intrinsic sphincter deficiency; BMI, body mass index; Qmax, maximum urinary flow rate; PVR, post voided residual urine; MUCP, maximum urethral closure pressure; VLPP, Valsalva leak point pressure; $\mathrm{Hb}$, hemoglobin.

$20 \mathrm{cmH}_{2} \mathrm{O}$ and the cure rates between two groups were $77 \%$ and $86 \%$, respectively, with no statistical differences [10].

In our study, the cure rates were $76.7 \%$ in ISD group and $75.3 \%$ in non ISD group after minimum three year follow-up, and there was no significant difference. These cure results were similar to success rates of previous studies and suggest that TVT is an effective treatment even in women with ISD after long term follow up with other studies $[9,10]$.

There is few data on factors influencing the outcome after mid urethral sling in ISD patients, including urodynamic findings. Paick et al. [2] analyzed 61 ISD women and reported that urge symptoms and low MUCP were independent factors for treatment failure.

Low MUCP as a prognostic factor was reported by other study [11] and Liapis et al. [3] reported low success rate in women with 'fixed' urethra. These results mean that adequate cooptation or mobility of the urethra is important for a successful outcome of the procedure.

Our results showed that the only VLPP was the significantly different between the subgroups of ISD patients. The mechanism of this result is probably that the lower VLPP means the more damaged components of the continence mechanism such 
as the external sphincter, levator musculature, pubourethral ligaments, urethropelvic ligaments, and urethra elasticity.

The major limitations of the study include the relatively small number of patients and the lack of objective outcome measures. Also, there was a possibility of selection bias during follow-up. Although low VLPP was only significant factor with TVT procedure failure in ISD patients, larger number of patients is needed to justify this results.

Despite of our limitations, our study has strong point in terms of long follow-up duration and identification of another prognostic factor of TVT in ISD patients.

Our findings suggested that ISD women can have successful long-term surgical outcomes after TVT procedures. However, clinicians should consider the possibility of TVT procedure failure in ISD women who have extremely low VLPP.

\section{CONFLICT OF INTEREST}

No potential conflict of interest relevant to this article was reported.

\section{REFERENCES}

1. Rezapour M, Falconer C, Ulmsten U. Tension-Free vaginal tape (TVT) in stress incontinent women with intrinsic sphincter deficiency (ISD): a long-term follow-up. Int Urogynecol J Pelvic Floor Dysfunct 2001;12 Suppl 2:S12-4.

2. Paick JS, Ku JH, Shin JW, Son H, Oh SJ, Kim SW. Tension-free vaginal tape procedure for urinary incontinence with low Valsalva leak point pressure. J Urol 2004;172(4 Pt 1):1370-3.

3. Liapis A, Bakas P, Salamalekis E, Botsis D, Creatsas G. Tension-free vaginal tape (TVT) in women with low urethral closure pressure. Eur J Obstet Gynecol Reprod Biol 2004;116:67-70.

4. Abrams P, Cardozo L, Fall M, Griffiths D, Rosier P, Ulmsten U, et al. The standardisation of terminology of lower urinary tract function: report from the Standardisation Sub-committee of the International Continence Society. Neurourol Urodyn 2002;21:167-78.

5. Gordon D, Gold RS, Pauzner D, Lessing JB, Groutz A. Combined genitourinary prolapse repair and prophylactic tension-free vaginal tape in women with severe prolapse and occult stress urinary incontinence: preliminary results. Urology 2001;58:547-50.

6. Doo CK, Hong B, Chung BJ, Kim JY, Jung HC, Lee KS, et al. Fiveyear outcomes of the tension-free vaginal tape procedure for treatment of female stress urinary incontinence. Eur Urol 2006;50:333-8.

7. Kuuva N, Nilsson CG. Long-term results of the tension-free vaginal tape operation in an unselected group of 129 stress incontinent women. Acta Obstet Gynecol Scand 2006;85:482-7.

8. Doo CK, Hong B, Chung BJ, Kim JY, Jung HC, Lee KS, et al. Fiveyear outcomes of the tension-free vaginal tape procedure for treatment of female stress urinary incontinence. Eur Urol 2006;50:333-8.

9. Kim NS, Bae JH, Lee JG. Long-term follow-up of the tension-free vaginal tape (TVT) procedure for treating female stress urinary incontinence. Korean J Urol 2006;47:729-33.

10. Meschia M, Pifarotti P, Buonaguidi A, Gattei U, Spennacchio M. Tension-free vaginal tape (TVT) for treatment of stress urinary incontinence in women with low-pressure urethra. Eur J Obstet Gynecol Reprod Biol 2005;122:118-21.

11. Sergent F, Popovic I, Grise P, Leroi AM, Marpeau L. Three-year outcomes of the tension-free vaginal tape procedure for treatment of female stress urinary incontinence with low urethral closure pressure. Gynecol Obstet Fertil 2006;34:692-700. 